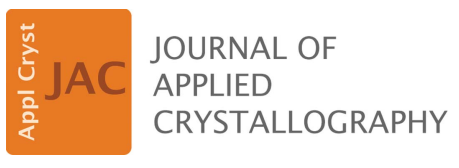

ISSN 1600-5767

\section{The Overproduction of Truth. Passion, Competition, and Integrity in Modern Science. By Gianfranco Pacchioni. Oxford University Press, 2018. Pp. 176. Price GBP 19.99 (hardback). ISBN 9780198799887.}

\author{
John R. Helliwell*
}

Department of Chemistry, University of Manchester, Manchester M13 9PL, UK. *Correspondence e-mail: john.helliwell@manchester.ac.uk

This book was first published in Italian under the title Scienza, 'quo vadis'? The author's web site makes clear that he is a highly accomplished scientist: 'author of more than 400 papers with about 15000 citations (h-index: 67) and has given about 300 invited talks at international conferences and research institutions. He received various awards including the Nasini Medal of the Italian Chemical Society (1994), the National Price 'Federchimica' (1996), the Alexander von Humbold Award (2005).' His science interests are listed as 'the electronic structure and the theoretical description of oxides (bulk, surface, thin films), of supported metal clusters and their role in surface chemistry, catalysis, photocatalysis and energy production'. So, this highly respected scientist has written his career-long look back from a deep knowledge of science and of scientists and makes a projection of where science is going.

Whilst I like the title of the Italian version, with its humble question mark, I reacted badly against the title The Overproduction of Truth of the OUP English version of the book, as a bald statement. In a world of fake news and a distrust of experts, an overproduction of truth as a necessary antidote must surely be a good thing, I think.

As I read this book, I again reacted badly, time and again, to the downbeat mood of the author's analyses. His summaries in effect look back to a happier time of fewer scientists, slower science involving fewer papers, and more convivial conferences without the large number of posters and basically not market driven. His view of the current situation is captured on p. 82: 'In a crowded world of mediocre scientists, it is not surprising that mediocre, irrelevant, and even wrong studies find their way to academic consecration by publication in a 'scientific journal'.' My best riposte is to say that with science funding agency grant-proposal success rates that I know of being around 10-25\%, and in my experience as a referee for many funding agencies with very few bad or flawed proposals, science standards and the stringent need for scientific integrity and excellent past track record are very, very exacting checks and balances. I feel that they counter the author's negative views of modern day science and scientists. Also, regarding posters at conferences, I enjoy these and the chance to meet the presenting scientists, be they early, mid or late career. I also strongly support initiatives to have poster prizes to encourage all concerned in the evaluation of these important contributions. Poster sessions as a whole also allow me to notice trends and upcoming golden nuggets.

The failure of science through frauds such as that of Hendrik Schön in materials science and that of Andrew Wakefield in vaccination studies are documented in detail in this book, but not really to show that the process of science scrutiny is working, including the vital importance of the underpinning data of studies, but instead as a forecast of worse to come. To document this, the author presents evidence of increasing instances of plagiarism in science publication. He presents the data for this assertion on p. 59. Again, I would counter that the internet, which may have expedited the cut-and-paste plagiarist, provides the antidote with the use of originality checking software embedded within proper peer review.

In asking 'Are we too many (scientists)?' the author is on more solid ground, as the funding agencies are indeed scrutinizing the numbers of $\mathrm{PhD}$ students being trained now with more attention paid to job prospects and career advice. 
The table of contents is shown below:

1. No progress without basic science

2. The way we were: make science in the last century

3. Publish or perish

4. Judges and defendants

5. Unit of measurement

6. Are we too many?

7. Famous frauds

8. Do we still believe in science?

The book concludes with the chapter Do we still believe in science? The answer should be a straightforward, you bet we do; the alternative is what? I think it better to conclude that science delivers. The author does say as much in short caveat style, here and there, to his main, downbeat, thesis 'the overproduction of truth'. One of the author's caveats is on p. 54: 'Today, thanks to powerful search engines, almost nothing escapes a careful and meticulous search.' To which I would add that internet tools such as Google Scholar track on a daily basis the citations to one's own publications. Twitter, which he also does not like, I find a highly useful tool for keeping up with my work interests. I assert then that keeping up is easier than in yesteryear. Another of his caveats is on p. 144: 'the world of science is and remains an essentially objective, sound system'.

Overall, there is much to commend in this book and I kept myself much more at ease with the Italian title of Science, where is it going? in my mind. The book is well written, lucid and interesting. Also, it is true that there are problems that the modern day researcher faces of judging if a conference enquiry or a journal's request to submit to them is fake, but these predatory entities are, most of the time, easily spotted and go straight into one's e-mail delete bin. And, the book is 'highly recommended' by Joel Bernstein, who sadly passed away recently and who many crystallographers know.

OUP have made a nice book jacket and yellow cloth cover. But there is no subject index, and with such a short contents listing this omission is a major oversight of the publisher. There are 92 end notes as factual citations to support the narrative, which is a good feature. I also like the evidencebased data plots in Figs. 2 (p. 46), 5 (p. 105) and 6 (p. 107), which again underpin the author's description of the expansion of science.

In conclusion, I believe that this expansion in the production of science and the steadily improving rigour of its procedures (resting wherever possible on open scientific data, including to referees) is a Public Good not a Public Bad. 